\title{
Manejo racional de resíduos da cultura do fumo (Nicotiana tabacum L.) para obtenção de composto orgânico
}

\author{
Rational management of tobacco (Nicotiana tabacum L.) crop \\ residues to obtain organic compost
}

\author{
Dário Costa Primo ${ }^{1 *}$; Francisco de Souza Fadigas²; José Carlos Ribeiro Carvalho²; \\ Carlos Daniel Seifert Schmidt ${ }^{3}$; Antonio Carlos Souza Borges Filho ${ }^{4}$
}

\begin{abstract}
Resumo
Os resíduos vegetais podem ser utilizados na produção de adubo orgânico por meio da compostagem. O objetivo deste estudo foi avaliar o efeito de dois inoculantes sobre a velocidade de decomposição do resíduo da cultura do fumo. O experimento foi conduzido em delineamento inteiramente casualizado, com três tratamentos e seis repetições, sendo o resíduo picado em picadeira e misturado aos inoculantes em betoneira. Foram avaliados os tratamentos: TF $+\mathrm{EB}+\mathrm{RB}-$ talo de fumo, esterco bovino e rúmen bovino; TF + EB + MP - talo de fumo, esterco bovino e microsept-pó e TF + EB - talo de fumo e esterco bovino. A temperatura e a umidade das pilhas foram monitoradas semanalmente. As pilhas foram revolvidas a cada 07 dias, inicialmente e a seguir a cada 14 dias até os 60 dias. Aos trinta, sessenta e noventa dias, foi feita a coleta, para análise química, do material em compostagem. Entre vinte e quarenta dias as pilhas mantiveram temperatura entre 57 e $60^{\circ} \mathrm{C}$. A mistura contendo rúmen bovino (RB) apresentou a menor temperatura após 40 dias. Ao final da compostagem a mistura contendo microsept-pó (MP) foi a que apresentou menor umidade. A relação $\mathrm{C} / \mathrm{N}$, do composto obtido, ficou entre 10/1 e 11/1. Os três tratamentos apresentaram pH fracamente alcalino na fase de cura. Pode-se considerar que 60 dias de compostagem são suficientes para a obtenção de um composto estabilizado a partir da mistura resíduo de fumo usando esterco, com ou sem a adição de inoculantes.
\end{abstract}

Palavras-chave: Resíduo agrícola, inoculantes, compostagem

\begin{abstract}
Crop residues may be used to produce organic composts for agricultural use. The aim of this study was to evaluate the effect of two inoculums on the decomposition speed of tobacco residues (stems). The experiment was carried out in a completely randomized design, with three treatments and six replications. The residue used in the study was passed through a forage chopper and mixed to the inoculums in a concrete truck mixer. The treatments evaluated were: $\mathrm{TF}+\mathrm{EB}+\mathrm{RB}$ - tobacco residue, bovine manure and bovine rumen; TF + EB + MP - tobacco residue, bovine manure and Microsept-Dust and TF + EB tobacco residue and bovine manure. The temperature and humidity of the piles were monitored weekly. The piles were initially turned up side down every seven days, and then every fourteen days till closing 60 days. Samples for chemical analysis of the composted material were collected at 30,60 and 90 days after the beginning of the composting process. The temperature of the piles stayed around 57 to $60{ }^{\circ} \mathrm{C}$ in
\end{abstract}

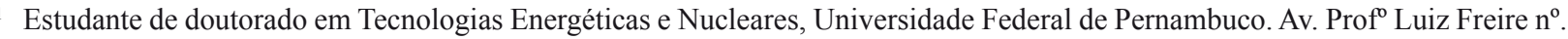
1000, Cidade Universitária. CEP 50740-540- Recife, PE. E-mail: darioprimo@gmail.com

2 Profs. Drs. da Universidade Federal do Recôncavo da Bahia. Campus Universitário, CEP 44380-000 Cruz das Almas, BA. E-mail: fadigas@ufrb.edu.br, Jcrc48@yahoo.com.br

3 Eng $^{\circ}$ Agr $^{\circ}$ MSc. em irrigação pela Universidade Federal do Recôncavo da Bahia, UFRB. Campus Universitário, CEP 44380-000 Cruz das Almas, BA. E-mail: danieldanco@gmail.com

4 Engo Agro. E-mail: acsbf@hotmail.com

* Autor para correspondência
}

Recebido para publicação 04/10/2010 Aprovado em 21/06/2011 
the period between the 20 to 40 days after the beginning of the composting process. The mix containing cattle rumen (RB) presented the lowest temperature after forty days. At the end of the composting the mix containing Microsept-Dust (MP) presented the lowest humidity. The $\mathrm{C} / \mathrm{N}$ relation of the composts obtained was around $10 / 1$ and $11 / 1$. The three treatments presented $\mathrm{pH}$ values close to the neutrality in the mature stage. A period of sixty days seems to be sufficient to obtain a mature and stable biocompost of tobacco waste using manure independent of the addition of inoculums.

Key words: Agriculture waste, inoculums, composting

\section{Introdução}

A partir da década de setenta, muita atenção passou a ser dada as demandas ambientais e à necessidade do desenvolvimento tecnológico com vistas à disposição dos resíduos agropecuários, agroindustriais, industriais e domésticos, de forma a causar o mínimo impacto sobre o meio ambiente. Apesar de bem antigo, o crescente interesse pela técnica da compostagem ressurgiu nas últimas décadas devido à necessidade do desenvolvimento de tecnologias de baixo custo para o tratamento de resíduos orgânicos (IMBEAH, 1998).

De maneira geral, todos os restos orgânicos vegetais ou animais encontrados poluindo o meio ambiente nas propriedades agrícolas podem ser utilizados na fabricação de composto orgânico (TEIXEIRA, 2002). A compostagem é um processo de decomposição aeróbia, no qual a matéria orgânica se transforma sob a ação de micro-organismos, em um adubo estável e rico em nutrientes, viabilizando a destinação adequada para os resíduos orgânicos (SANTOS; LIMA; CARVALHO, 2002).

Com esta perspectiva, a compostagem constitui uma solução bastante apropriada em razão de permitir a redução de custos e produzir composto orgânico. A reciclagem de resíduos agrícolas por meio da compostagem, além de auxiliar na redução de impacto ambiental ainda promove a geração de insumos orgânicos para a agricultura, o que é um dos aspectos mais importantes envolvidos no sistema de produção (BARDOS; HADLEY; KENDLE, 1992). O composto orgânico é um material húmico que pode ser aplicado no solo, principalmente nos arenosos pobres em humus, melhorando suas propriedades físicas químicas e biológicas (GROSSI, 1993).
Os materiais de origem animal e vegetal utilizados no preparo de compostos orgânicos podem ser os mais variados como o esterco e rúmen bovino, a palha de cereais e de leguminosas, os resíduos de culturas, as folhagens, as graminhas e outros detritos vegetais que não tenham melhor aproveitamento (PAIVA, 2001). O uso de esterco de animais ricos em micro-organismos acelera a decomposição dos restos vegetais e enriquece o produto final (RAIJ, 1996).

A utilização de resíduos de origem vegetal ou animal para enriquecimento do composto possibilita, também, retenção dos nutrientes minerais pelas substâncias húmicas e sua liberação gradativa as plantas, o que pode contribuir para a diminuição dos parcelamentos da adubação e, consequentemente, com a redução dos custos com mão-de-obra (ARANGO; GONZÁLES, 1999). A compostagem é uma prática difundida e o efeito benéfico do composto orgânico no beneficiamento de solos e no desenvolvimento vegetal é bastante conhecido (DIAS; VAZ, 1996).

De acordo com Singh e Sharma (2002), a adição de micro-organismo favorece a decomposição inicial dos resíduos orgânicos, o que reduz o tempo da compostagem, desta forma, o esterco bovino pode funcionar como fonte de micro-organismos e promover redução do tempo da maturação do composto. O processo se torna bastante acelerado se houver inoculação nas diversas camadas dos materiais orgânicos, com produtos contendo bactérias como, por exemplo, esterco e estrume líquido (LOUREIRO et al., 2007). Segundo Kiehl (2004), é importante que se adicionem, à pilha de compostagem, materiais ricos em nitrogênio, 
como resíduo de matadouro, estercos animais, tortas vegetais e outros resíduos que entrem em decomposição fácil e prontamente.

A cultura do fumo possui destaque socioeconômico no recôncavo baiano, havendo várias indústrias fumageiras na região com alta produção de folhas para fabricação de charuto gerando em torno de $75 \%$ de resíduo, em relação à biomassa total cultivada. Essa atividade gera como subproduto, quantidade significativa de resíduos (talos, folhas novas, flores e raízes) ao final do ciclo da cultura, em virtude de apenas parte das folhas serem aproveitadas para comercialização. Dessa forma, obtém-se grande quantidade de resíduo orgânico poluente, porém potencialmente compostável, por possuir baixa velocidade de decomposição. Assim, a compostagem desse resíduo utilizando diferentes tipos de inoculantes com o intuito em degradar de forma rápida a nicotina, representa uma alternativa para solucionar a disposição final do subproduto gerado no cultivo de fumo e a possibilidade de utilização do composto orgânico, por exemplo, em projetos de reflorestamento. Diante do exposto, este estudo teve por objetivo avaliar o efeito de diferentes inoculantes sobre a velocidade de decomposição dos resíduos da cultura do fumo.

\section{Material e Métodos}

O trabalho experimental foi realizado na Fazenda Capivari, de propriedade da empresa Danco, localizada no município de Governador Mangabeira, Bahia, a uma altitude de $225 \mathrm{~m} \mathrm{e}$ coordenadas de $12^{\circ} 48^{`} 38^{\prime \prime}$ 'de latitude e $39^{\circ} 05^{`} 17^{\prime \prime}$ de longitude. O solo da região é classificado como Latossolo Amarelo álico, textura franco-argiloarenosa, apresentando horizontes subsuperficiais coesos e relevo plano. A vegetação típica do local é a floresta estacional semidecidual; seu clima é úmido a subúmido e pluviosidade média anual de $1.141 \mathrm{~mm}$, sendo os meses de março a agosto os mais chuvosos e os de setembro a fevereiro os mais secos; a temperatura média anual é de $23.8^{\circ} \mathrm{C}$ (EMBRAPA, 2007).

O experimento foi conduzido durante o periodo de dezembro de 2007 a março de 2008, tendo sido instalado em galpão com dimensões de 10 x 20 x $3 \mathrm{~m}$ construído em madeira de eucalipto e coberto com lona plástica preta, mantendo-se as laterais livres para ventilação.

Os talos de fumo foram triturados em picadeira elétrica e reduzidos a pedaços com tamanho entre 2 e $5 \mathrm{~cm}$; em seguida, o material triturado foi misturado em betoneira para compor as seguintes misturas em volume de cem litros: $\mathrm{TF}+\mathrm{EB}+\mathrm{RB}$ talo picado $(85 \%)+$ esterco bovino $(15 \%)+$ rúmen bovino fresco (4 L dissolvidos em $20 \mathrm{~L}$ de água); $\mathrm{TF}+\mathrm{EB}+\mathrm{MP}$ - talo picado $(85 \%)+$ esterco bovino $(15 \%)+$ microsept-pó $(2 \mathrm{~kg}$ dissolvidos em $20 \mathrm{~L}$ de água) e TF + EB - talo picado (85\%) + esterco bovino (15\%), constituindo assim três diferentes tratamentos dispostos em delineamento experimental inteiramente casualisado, com seis repetições. As características dos materiais utilizados na compostagem para formação de cada pilha estão descritas na (Tabela 1).

Tabela 1. Caracterização dos materiais e quantidade utilizada para cada pilha de compostagem.

\begin{tabular}{lccc}
\hline Materiais & $\mathbf{p H}$ & Umidade & Quantidade por pilha \\
\hline Talos de Fumo & 7,4 & $79,4 \% \mathrm{~mm}^{-1}$ & $1.275 \mathrm{~L}$ \\
Esterco Bovino & 7,0 & $50 \% \mathrm{~mm}^{-1}$ & $225 \mathrm{~L}$ \\
Inoculante Rúmen & 7,2 & $80 \% \mathrm{~mm}^{-1}$ & $4 \mathrm{~L}$ em $20 \mathrm{~L}$ de água \\
Microsept-Pó & 6,0 & $40 \% \mathrm{~mm}^{-1}$ & $2 \mathrm{~kg} \mathrm{em} 20 \mathrm{~L}$ de água
\end{tabular}


Após a mistura, o material foi disposto em pilhas de formato cônico, com volume de 1,5 $\mathrm{m}^{3}, 1,20$ $\mathrm{m}$ de base e 1,30 $\mathrm{m}$ de altura. Obteve-se o rúmen bovino fresco do abatedouro Frisaj e o MicroseptPó (coquetel de micro-organismos) da empresa Bioclean do Brasil. Para evitar perda rápida de umidade, as pilhas foram cobertas com as raízes previamente separadas dos talos. Para fins de avaliação, a temperatura das pilhas foi medida desde o início da compostagem ate o período de 90 dias, a cada intervalo regular de uma semana, no topo, no centro e na base das pilhas, com uso de termômetro digital, obtendo-se a média dos três pontos.

Para o controle da umidade das pilhas efetuaramse, semanalmente, a coleta de amostras e secagem em estufa de ventilação forçada $\left(a 65^{\circ} \mathrm{C}\right)$ e pesagem em balança semianalítica $(0,001 \mathrm{~g})$, utilizando-se o método adaptado de Kiehl (1985). Para manter a umidade entre 55 e $64 \%$, segundo Kiehl (1985), as pilhas foram irrigadas manualmente, com regador, durante o reviramento, e adicionados 24 litros de água no primeiro mês, $16 \mathrm{~L}$ no segundo e $8 \mathrm{~L}$ no terceiro.

Realizou-se o reviramento das pilhas a cada 07 dias no primeiro mês e a cada 14 dias nos segundo e terceiro meses, procurando-se misturar as camadas externas (mais secas) e as internas (mais úmidas) no sentido de oxigenar o material e favorecer a atuação dos micro-organismos decompositores. Para caracterização química analisou-se a relação $\mathrm{C} / \mathrm{N}$ no material recém-triturado e, aos trinta, sessenta, noventa e cento e vinte dias, no material em compostagem. A determinação do $\mathrm{pH}$ foi feita em amostras no material triturado aos trinta, sessenta e noventa dias de compostagem. Para obtenção do teor de nitrogênio total presente em cada amostra, pesou-se $0,1 \mathrm{~g}$ do composto seco $\left(65^{\circ} \mathrm{C}\right)$ e as análises químicas foram realizadas nos extratos obtidos por digestão sulfúrica, pelo método do azul-de-salicílico (ROCHA; GRANER; MAGNANI, 1989). Obtevese o carbono por oxidação com dicromato (via úmida) e titulação com sulfato ferroso amoniacal, segundo Okalebo, Cathua e Woomer (1999). A determinação da capacidade de retenção de água do composto final das amostras foi feita por saturação em água, seguida de secagem em estufa, pelo método de \% CRA descrito por Kiehl (1985).

\section{Resultados e Discussão}

A variação da temperatura dos tratamentos durante o processo de compostagem (Figura 1). ocorreu da forma descrita por Pereira Neto (1996) e Kiehl (1998). A temperatura das misturas no momento da montagem do experimento foi de 32 ${ }^{\circ} \mathrm{C}$ (Figura1). As pilhas de compostagem, de forma similar nos três tratamentos, atingiram temperatura média entre 68 e $70{ }^{\circ} \mathrm{C}$ nos primeiros sete dias. Entre vinte e quarenta dias as pilhas mantiveram temperatura média entre 57 e $60^{\circ} \mathrm{C}$ e, partir desse tempo de compostagem, a temperatura foi decaindo, até os setenta dias.

A partir dos 70 dias de compostagem, ocorreu diminuição da temperatura em todos os tratamentos até atingir a temperatura ambiente de $32{ }^{\circ} \mathrm{C}$, mantendo-se assim até ao final do processo. Com base em trabalhos realizados por Junho, Romero e Bruna (2004), esta diminuição de temperatura com o aumento do tempo de compostagem, era prevista.

O Tratamento em que se utilizou rúmen bovino (RB) como inoculante, apresentou menor valor estatístico de temperatura após os 40 dias (Figura 1) quando comparado com os demais, indicando ter sido o primeiro a atingir o processo de bioestabilização. Este comportamento decorre, provavelmente, da presença de protozoários pertencentes ao gênero Entodinium, que predominam na fauna ruminal e possuem capacidade de digestão de carboidratos da parede celular das plantas e degradação da celulose, hemicelulose, lignina, amido e proteína (DEHORITY, 1991).

Vários estudos de protozoologia ruminal têm mostrado a presença de atividades hemicelulolítica e celulolítica nos ciliados, especialmente nos grandes entodiniomorfos. Jouany e Senaud (1979), 
observaram aumento significativo da digestibilidade da lignocelulose, de 3 a 10\%, devido à presença de ciliados no rúmen. $\mathrm{O}$ tratamento contendo $\mathrm{TF}+\mathrm{EB}$ (Figura 1) foi o que apresentou maior temperatura e acima de $40{ }^{\circ} \mathrm{C}$ entre 30 e 60 dias. Segundo Pereira Neto (1996), os valores de temperatura decaem para valores menores que $40{ }^{\circ} \mathrm{C}$ na fase termofílica no final do processo da compostagem, dando início à fase mesofílica, em geral entre 30 a 60 dias.
Os resultados obtidos no presente estudo, indicaram que o processo de compostagem tenha sido mais lento na ausência de inoculante. Observouse que todos os tratamentos se mantiveram com temperaturas superiores a $50{ }^{\circ} \mathrm{C}$ entre 07 e 49 dias, indicando que a fase termofílica se estendeu além do período normalmente mencionado pela literatura correlata.

Figura 1. Variação da temperatura dos tratamentos em função do tempo de compostagem.

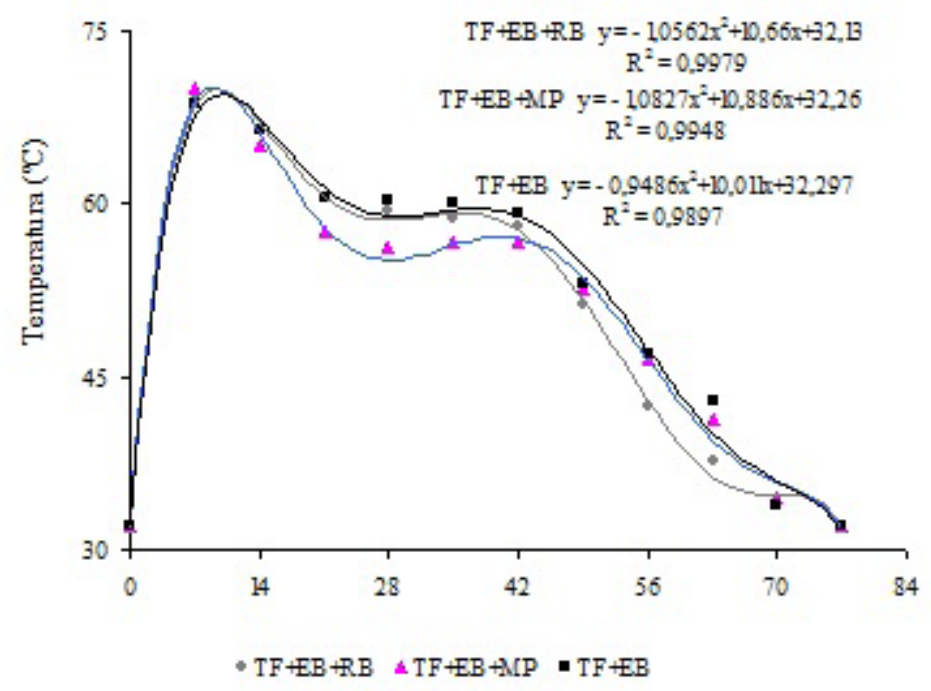

Segundo Junho, Romero e Bruna (2004), o prolongamento da fase termofílica está relacionado a outros fatores responsáveis pela geração de calor, como o tipo de micro-organismo presente na biomassa, umidade, granulometria das partículas da matéria-prima, intervalo de reviramento (aeração) e da relação $\mathrm{C} / \mathrm{N}$ da biomassa utilizada.

A temperatura no processo de compostagem exerce efeito sobre a taxa de consumo de oxigênio pelos micro-organismos, tendo-se constatado que o valor ótimo ronda aos 50 e $55^{\circ} \mathrm{C}$ (FINSTEIN, 1982). Outros estudos realizados por Waksman e Skinner (1985), sugerem valores entre 45 e $70{ }^{\circ} \mathrm{C}$ como ótimos. Morel et al. (1992), afirma que o intervalo de temperatura em compostagem entre 45 e $59^{\circ} \mathrm{C}$ é o que mais favorece a decomposição da matéria orgânica.

A umidade das misturas no início do processo da compostagem em todos os tratamentos, (Figura 2) que era cerca de $79 \%$ (mm-1), decresceu nos dias seguintes para valores entre 55 e $60 \%$ (mm1), sendo mantida nesta faixa até aos 90 dias (Figura 2). O Tratamento TF + EB + RB foi o que, estatisticamente, apresentou menor oscilação nos valores de umidade durante o processo, em relação aos demais (Figura 2). 
Figura 2. Variação no teor de umidade dos tratamentos durante a compostagem.

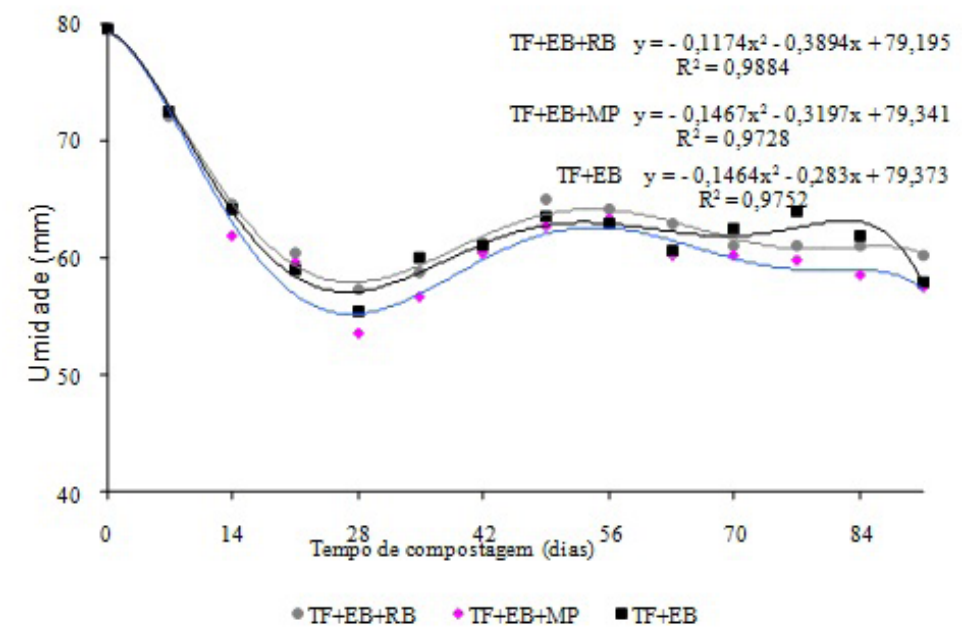

Ao final do tempo de compostagem, a mistura contendo o inoculante Microsept-Pó (MP) foi a que apresentou menores médias de umidade, fato relacionado com a menor capacidade de retenção de água deste tratamento. O teor de umidade é um dos parâmetros que devem ser monitorados durante a compostagem para que o processo se desenvolva satisfatoriamente (PROSAB, 1999).

Os dados mostram que a umidade foi mantida dentro dos padrões estabelecidos pela literatura correlata, que deve situar-se de 45 a $65 \%$ (FINSTEIN; MILLER, 1985); deste modo, as condições ideais de umidade possibilitaram a expressão do efeito dos tratamentos, visto ser este um dos fatores mais limitantes ao processo.

A (Tabela 2) demonstra os valores da concentração de carbono e nitrogênio na matéria-prima (TF), no início, durante e no final da compostagem. Os valores de C $(37,8 \%)$ e de $\mathrm{N}(1,70 \%)$ na matéria-prima são valores considerados para o processo de compostagem, uma vez que proporcionam uma relação $\mathrm{C} / \mathrm{N}$ na faixa de $30 / 1$. Durante o processo da compostagem os valores referentes ao $\mathrm{C}$ decaíram, estabilizando-se aos 90 dias entre 12 e $14 \%$, enquanto os de $\mathrm{N}$ aumentaram no final do processo, o que era previsto.

Em análises realizadas por pesquisadores da Embrapa Mandioca e Fruticultura Tropical (EMBRAPA, 2005), com resíduos de fumo secado a $110{ }^{\circ} \mathrm{C}$ foram encontrados resultados semelhantes no teor de carbono $(39,06 \%)$ e na relação $\mathrm{C} / \mathrm{N}$ (18/1). A maior perda de $\mathrm{C}$ foi registrada no tratamento $\mathrm{TF}+\mathrm{EB}+\mathrm{MP}$. É possível que a presença do inoculante microseptpó, tenha contribuído para elevar o $\mathrm{pH}$, provável, portanto, de possibilitar maiores perdas de $\mathrm{C}$ como consequência da atividade microbiana no ambiente (IYENGAR; BHAVE, 2005). Mees, et al. (2009), em trabalhos realizados com compostagem afirmou que o conteúdo de carbono diminuiu com o progresso da decomposição. 
Tabela 2. Teor de C, N (\%) e relação C/N da matéria-prima e dos compostos, no inicio, durante e no final da compostagem.

\begin{tabular}{lccccc}
\hline & Tratamentos & Época & \multicolumn{2}{c}{ Avaliação } & (Dias) \\
\cline { 2 - 6 } & $\mathbf{0}$ & $\mathbf{3 0}$ & $\mathbf{6 0}$ & $\mathbf{9 0}$ & $\mathbf{1 2 0}$ \\
\hline $\mathrm{TF}$ & & & & & \\
$\mathrm{C}$ & 37.8 & & & & \\
$\mathrm{~N}$ & 1.70 & & & & \\
$\mathrm{C} / \mathrm{N}$ & $22 / 1$ & & & & \\
$\mathrm{TF}+\mathrm{EB}+\mathrm{RB}$ & & & & & \\
$\mathrm{C}$ & 27.0 & 21.2 & 19.5 & 16.2 & 14.4 \\
$\mathrm{~N}$ & 1.10 & 1.10 & 1.60 & 1.60 & 1.40 \\
$\mathrm{C} / \mathrm{N}$ & $24 / 1$ & $19 / 1$ & $12 / 1$ & $10 / 1$ & $10 / 1$ \\
$\mathrm{TF}+\mathrm{EB}+\mathrm{MP}$ & & & & & \\
$\mathrm{C}$ & 30.6 & 23.3 & 18.8 & 15.6 & 12.6 \\
$\mathrm{~N}$ & 1.10 & 1.10 & 1.10 & 1.20 & 1.30 \\
$\mathrm{C} / \mathrm{N}$ & $28 / 1$ & $21 / 1$ & $17 / 1$ & $13 / 1$ & $10 / 1$ \\
$\mathrm{TF}+\mathrm{EB}$ & & & & & \\
$\mathrm{C}$ & 29.1 & 26.0 & 18.0 & 16.5 & 14.5 \\
$\mathrm{~N}$ & 1.10 & 1.40 & 1.40 & 1.50 & 1.30 \\
$\mathrm{C} / \mathrm{N}$ & $26 / 1$ & $18 / 1$ & $12 / 1$ & $11 / 1$ & $11 / 1$ \\
\hline
\end{tabular}

A maioria dos micro-organismos decompositores necessita de carbono como fonte de energia e nitrogênio para a síntese de proteína sendo que, por esta razão, a relação $\mathrm{C} / \mathrm{N}$ é considerada o fator que melhor caracteriza o equilíbrio dos substratos. Independentemente da relação $\mathrm{C} / \mathrm{N}$ inicial, no final da compostagem esta converge para valor entre 10 e 20, devido a maiores perdas e imobilização de carbono que de nitrogênio, no desenvolvimento do processo (PROSAB, 1999); contudo, pela lei $\mathrm{n}^{\circ}$. 4.954, de 14 de janeiro de 2004, do Ministério da Agricultura, Pecuária e Abastecimento, a relação $\mathrm{C} / \mathrm{N}$ no composto orgânico comercial nunca deve ser superior a 18/1. A relação C/N é um dos fatores que devem ser observados no sentido de que, no início da decomposição, a média dos materiais misturados na pilha esteja dentro da faixa que vai de 25:1 a 35:1 (RINK, 1992).
O índice de maturidade do composto produzido, dado pela relação $\mathrm{C} / \mathrm{N}$, ficou entre 10 e 11 no final do processo de compostagem, indicando que os compostos se encontravam totalmente estáveis após 120 dias de compostagem (Tabela 3). Segundo diversos autores, uma relação $\mathrm{C} / \mathrm{N}$ abaixo de 15 expressa boa estabilidade do composto (HORTENSTINE; ROTHWELL, 1973; KROPISZ; WOJCIECHOWSKI, 1978; CHANYASAK; KUBOTA, 1981).

De acordo com Jimenez e Perez Garcia (1992a, 1992b), uma relação abaixo de 12 indica alto grau de maturidade do composto. Basicamente, a relação $\mathrm{C} / \mathrm{N}$ é utilizada como bom indicador da estabilidade biológica do composto, definindo a qualidade do produto resultante da compostagem de resíduos (MOREL et al., 1992). Tendo em vista que os compostos obtidos pelas três misturas já 
apresentavam relação C/N menor que 18/1 aos 60 dias após o início da compostagem, podese considerar esse tempo como suficiente para obtenção de um composto estável, não havendo necessidade de reviramento a partir deste momento.

$\mathrm{O}$ valor do $\mathrm{pH}$ obtido (Figura 3) na biomassa, no início da compostagem, foi de 7,4 nos três tratamentos, permanecendo alcalino durante todo o processo. Os tratamentos $\mathrm{TF}+\mathrm{EB}+\mathrm{RB}$ e $\mathrm{TF}+$ $\mathrm{EB}+\mathrm{MP}$ aos 90 dias, quando o composto já estava em fase de cura, apresentaram $\mathrm{pH}$ próximo ao valor inicial enquanto o tratamento apenas com esterco bovino se manteve com $\mathrm{pH}$ acima deste valor. De modo geral, os valores de $\mathrm{pH}$ na faixa alcalina estão dentro do esperado para compostos orgânicos (VILLAS BOAS et al., 1999; TEJADA et al., 2001).

Figura 3. Valores do $\mathrm{pH}$ dos três tratamentos durante a compostagem.

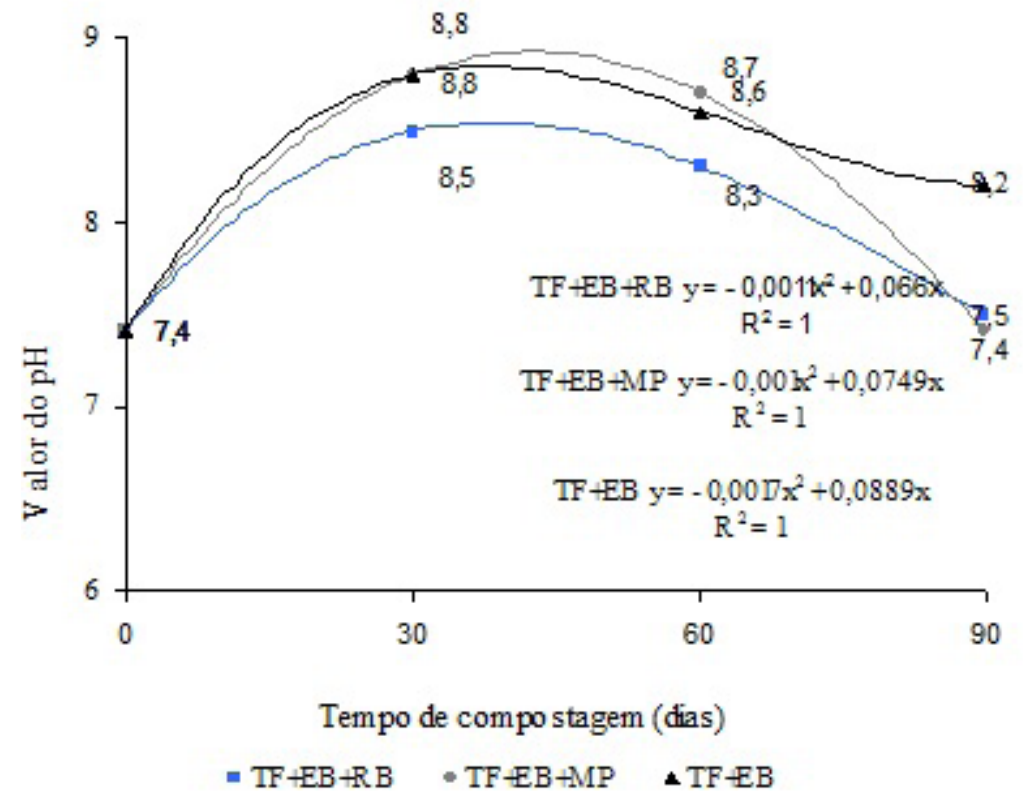

Um conjunto de fatores contribui para alterações do $\mathrm{pH}$ ao longo do processo de compostagem, haja vista que ocorre a formação de ácidos solúveis (ácidos carboxílicos de cadeia curta, ácido acético, propiônico, butírico e valérico) no início da compostagem, os quais são convertidos a dióxido de carbono pela ação microbiana (IYENGAR; BHAVE, 2005). Segundo Moreira e Siqueira (2002) a elevação do $\mathrm{pH}$ nos tratamentos até aos trinta dias do processo de compostagem pode ser consequência do processo de nitrificação. A medida em que este processo se desenvolve o $\mathrm{pH}$ do composto se eleva devido à maior concentração de bases (cálcio, magnésio, sódio e potássio) que contribui indiretamente para a obtenção de um material mais alcalino (KIEHL, 2002).
Esta característica é bastante desejável quando se pensa no uso agrícola de composto. Os resultados obtidos mostraram que a temperatura pode ter exercido alguma influência no valor do $\mathrm{pH}$ para o tratamento $\mathrm{TF}+\mathrm{EB}$ que permaneceu com temperaturas maiores na fase termofilica, ao contrário do que foi descrito por Kiehl (1985) e Pereira Neto (1996). Os três compostos produzidos atendem às exigências da legislação $\mathrm{n}^{\mathrm{o}}$. 4.954, de 14 de janeiro de 2004, pertinente a compostos, em relação ao $\mathrm{pH}$ e à relação $\mathrm{C} / \mathrm{N}$, cujos valores estão dentro dos padrões estabelecidos.

Os três compostos obtidos apresentaram cerca de $250 \%$ do seu próprio peso seco em água, o que representa metade do que seria retido pelo humus puro, conferindo-lhes excelentes características 
para uso agrícola. Um fertilizante bem humificado pode reter uma quantidade de água igual a $150 \%$ ao seu próprio peso. O humus puro, isolado da matéria orgânica, chega a reter $500 \%$ do seu próprio peso em água (KIEHL, 1985).

Os compostos $\mathrm{TF}+\mathrm{EB}+\mathrm{RB}$ e $\mathrm{TF}+\mathrm{EB}$, apresentaram maior capacidade de retenção de água, embora as médias não tenham sido excessivamente discrepantes (Figura 4). Sempre que a matéria orgânica se humifica, micelas coloidais se formam, elevando a capacidade de retenção de água (KIEHL, 2004).

$\mathrm{O}$ composto $\mathrm{TF}+\mathrm{EB}+\mathrm{MP}$ apresentou menor capacidade de retenção de água; supõe-se que a menor retenção esteja relacionada ao teor de $\mathrm{C}$ contido nesse composto; por outro lado, na medida em que se reduz o tamanho das partículas de uma matéria-prima pela compostagem, seus micrósporos aumentam e, consequentemente, a capacidade de reter água.

Figura 4. Capacidade de retenção de água dos compostos obtidos.

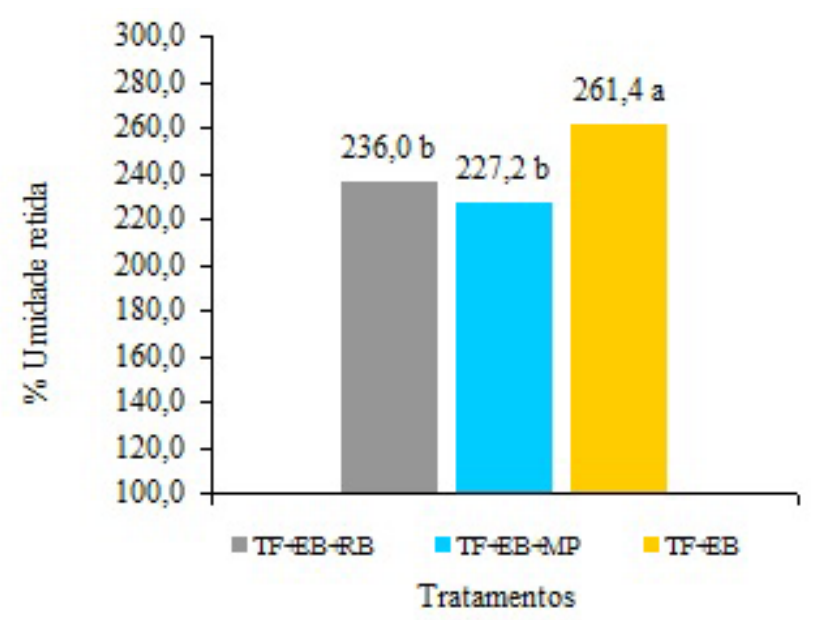

\section{Conclusões}

A técnica da compostagem é uma alternativa importante e viável de transformação de resíduos vegetais e animais em composto orgânico, o qual pode ser utilizado como adubo em sistemas agrícolas. Por meio da compostagem é possível também implementar a destinação inteligente e ecologicamente viável de resíduo (talos, folhas novas e flores) originado após a colheita do fumo. É possível obter-se um composto orgânico de boa qualidade a partir da mistura de talos de fumo e esterco bovino, com adição ou não de rúmen bovino ou microsept-pó como inoculante.

Pode-se considerar 60 dias de compostagem como tempo suficiente para a obtenção de composto orgânico de resíduo de fumo devidamente picado e misturado com esterco bovino. A utilização de esterco e rúmen bovino é importante em processo de compostagem de resíduos provenientes da cultura do fumo por serem de fácil aquisição e favorecerem rápida decomposição. A utilização de rúmen diminuiu o tempo de compostagem desse resíduo.

\section{Referências}

ARANGO, G.; GONZÁLEZ, H. Cambios químicos durante la compostación de resíduos de cosecha. Suelos Ecuatoriales, Colombia, v. 29, n. 1, p. 25-31, 1999.

BARDOS, R. P.; HADLEY, P.; KENDLE, A. Compost standards without tears - some ideas from the U.K. In: JACKSON, D. V.; MERILLOT, J. M.; L'HERMITE, P. (Ed.). Composting and compost quality assurance 
criteria. Brussels: Commission of the European, 1992. p. 294-325.

CHANYASAK, V.; KUBOTA, H. Carbon organic nitrogen ratio in water extracts as measure of compost degradation. Journal of Fermentation Technology, Japan, v. 59, n. 3, p. 215-219, 1981.

DEHORITY, B. A. Ciliate protozoa in the rumen of Brazilian water buffalo, Bubals Linnaes. Journal Protozooly, Cincinnati, v. 26, n. 4, p. 536-544. 1991.

DIAS, F. S. M.; VAZ, L. M. S. Compostagem aeróbica: tratamento dado ao lixo gerado no campus da universidade estadual de Feira de Santana, Bahia. Rio de Janeiro: ABES. 1996. 48 p.

EMPRESA BRASILEIRA DE PESQUISA AGROPECUÁRIA - EMBRAPA. Compostagem caseira de lixo orgânico doméstico. Cruz das Almas: Embrapa CNPMFT, 2005. 12 p. (Circular técnica, 76).

Levantamento detalhado dos solos do centro nacional de pesquisa de mandioca e fruticultura tropical. Cruz das Almas: EMBRAPA, 2007. 58 p.

FINSTEIN, M. S. Temperature implications for process design and control, composting. In: PRESS, G. J.; FINSTEIN, M. S. (Ed.). Composting: theory and practice for city, industry and farm. [S.1]: Ed. J. G. Press, 1982. p.150-157.

FINSTEIN, M. S.; MILlER, F. C. Principles of composting leading to maximization of decomposition rate, odour control and cost effectiveness. In: GASSER, J. K. R. (Ed.). Composting of agricultural and other wastes. London: Elsevier Applied 1985. p. 13-26.

GROSSI, M. G. L. Avaliação da qualidade dos produtos obtidos de usinas de compostagem brasileiras de lixo doméstico através de determinações de metais pesados e substâncias orgânicas tóxicas. 1993. Tese (Doutorado em Química Analítica) - Universidade São Paulo, São Paulo.

HORTENSTINE, C. C.; ROTHWELL, D. F. Pelletized municipal refuse compost as a soil amendment and nutrients sourse for sorghum. Journal of Environmental Quality, Madison, v. 2, p. 343-345, 1973.

IMBEAH, M. Composting piggery waste: areview. Bioresource Technology, Oxford, v. 63, n. 3, p. 197-203, 1998.

IYENGAR, S. R.; BHAVE, P. P. In-vessel composting of household wastes. Waste Management, 2005. Disponível em: $<$ http://www.sciencedirect.com $>$. Acesso em: 8 maio 2008.

JIMENEZ, E. I.; PEREZ-GARCIA, V. Composting of domestic refuse and sewage sludge. II. Evolution of carbon and some "humification" index. Resources, Conservation and Recycling, Netherlands, v. 6, p. 246257, 1992a.

Determination or maturity indices for city refuse composts. Agriculture, Ecosystems and Environmental, Switzerland, v. 38, n. 4, p. 331-343, 1992 b.

JOUANY, J. P.; SENAUD, J. Role of rumen protozoa in the digestion of food cellulosic materials. Annual Rech Veterinary, West Lafayette, v. 10, n. 2, p. 261-263, 1979.

JUNHO, A. P.; ROMERO, M. de A.; BRUNA, G. C. Curso de gestão ambiental. São Paulo: Manole, 2004. $386 \mathrm{p}$.

KIEHL, E. J. Fertilizantes orgânicos. Piracicaba: Agronômica Ceres. 1998. 393 p.

. Fertilizantes orgânicos. São Paulo: Agronômica Ceres, 1985. 492p.

Manual de compostagem: maturação e qualidade do composto. 4. ed. Piracicaba: Agronômica Ceres, 2004. $173 p$.

KIEHL, J. K. Manual de compostagem: maturação e qualidade do composto. 3. ed. Piracicaba: Agronômica Ceres, 2002. 171 p.

KROPISZ, A.; WOJCIECHOWSKI, J. Mutual effects of mineral fertilizers and compost made from municipal wastes on yields and chemical composition of cabbage. Roczniki Nauk Rolniczych, Warszawa, v. 3, n. 2, p.164180, 1978.

LOUREIRO, D. C.; AQUINO, A. M. de, ZONTA, E.; LIMA, E. Compostagem e vermicompostagem de resíduos agrícolas com esterco bovino para a produção de insumo orgânico. Pesquisa Agropecuária Brasileira, Brasília, v. 42, n. 7, p. 1043-1048, 2007.

MEES, J. B. R.; DAMASCENO, S.; BOAS, M. A. V.; FAZOLO, A.; SAMPAIO, S. C. Estabilização da biomassa de aguapé através da compostagem com águas resíduárias de suínos e resíduos de frigorífico. Semina: Ciências Agrárias, Londrina, v. 30, n. 3, p. 709-716, 2009.

MOREIRA, F. M. S.; SIQUEIRA, J. O. Microbiologia e bioquímica do solo. Lavras: UFLA, 2002. $626 \mathrm{p}$.

MOREL, J. L.; COLIN, F.; GERMON, J. G. P.; JUSTE, C. Methods for the evaluation of the maturity of municipal refuse compos. In: GASSER, J. K. R. (Ed.). Composting of agricultural and other wastes. London: Elseveier Applied Science Publishers, 1992. p. 56-72.

OKALEBO, J. R.; CATHUA, K. W.; WOOMER, P. L. Laboratory methods of soil plant analysis: a woking manual. Nairob: TSBF/UNESCO, Rosta, 1999. 47 p. 
PAIVA, H. N. Produção de mudas. Viçosa: Aprenda Fácil, 2001. $130 \mathrm{p}$.

PEREIRA NETO, J. T. Manual de compostagem. Belo Horizonte: UFV/SLU/ UNICEF 1996. 56 p.

PROGRAMA DE PESQUISA EM SANEAMENTO BÁSICO - PROSAB. Manual prático para a compostagem de biossólidos. Londrina: UEL, 1999. 84 p.

RAIJ, B. van. Recomendações de adubação e calagem para o Estado de São Paulo. 2. ed. Campinas: Instituto Agronômico. Fundação IAC, 1996. 28 p.

RINK, R. Composting methods. In: . On-form composting handbook. Ithaca: Northeast Regional Agricultura Engineering Servic/Coopeative Extension, 1992. p. 47.

ROCHA, J. C.; GRANER, C. A. F.; MAGNANI, R. Determinação espectrofotométrica de amônio em extratos de carne, com salicilato e hipoclorito, sem prévia neutralização dos digeridos sulfúricos. Química Nova, São Paulo, v. 12, n. 4, p. 123, 1989.

SANTOS, A. A. do E.; LIMA, J. S.; CARVALHO, G. C. de. Técnicas de aplicação de composto orgânico, proveniente de resíduos urbanos domésticos, no desenvolvimento vegetal. In: SIMPÓSIO ÍTALO BRASILEIRO DE ENGENHARIA SANITÁRIA E AMBIENTAL, 6., 2002. Vitória. Anais... ABES, 2002, p. 1-6.

SINGH, A.; SHARMA, S. Composting of a crop residue through treatment with microorganisms and subsequent vermicomposting. Bioresource Technology, Oxiford, v. 85, n. 8, p. 107-115, 2002.

TEIXEIRA, R. F. F. Compostagem. In: HAMMES, V. S. (Org.). Educação ambiental para o desenvolvimento sustentável. Brasília: Embrapa Informação Tecnológica, 2002, v. 5, p. 120-123.

TEJADA, M.; DOBAO, M. M.; BENITEZ, C.; GONZALEZ, J. L. Study of composting of cotton residues. Bioresource Technology, Oxiford, v. 79, n. 1, p. 199-202, 2001.

VILLAS BOAS, R. L.; PASSOS, J. C.; BÜLL, T.; FERNANDES, D. M. Efeito de doses e tipos de composto orgânico na produção de alface (Lactuca sativa L.). In: CONGRESSO BRASILEIRO DE CIÊNCIA DO SOLO, 27., 1999, Brasília. Anais... Brasília: Sociedade Brasileira de Ciência do Solo, 1999. CD-ROM.

WAKSMAN, S. A.; SKINNER, C. E. Microorganisms concerned in the decomposition of cellulose in the soil. Journal Protozooly, Cincinnati, v. 12, p. 57-84, 1985. 
